\title{
Voice hearers' experiences of the Making Sense of Voices in an NHS setting
}

Article

Accepted Version

Steel, C., Schnackenberg, J., Travers, Z., Longden, E., Greenfield, E., Meredith, L., Perry, H. and Corstens, D. (2020) Voice hearers' experiences of the Making Sense of Voices in an NHS setting. Psychosis, 12 (2). pp. 106-114. ISSN 17522439 doi: https://doi.org/10.1080/17522439.2019.1707859 Available at https://centaur.reading.ac.uk/91058/

It is advisable to refer to the publisher's version if you intend to cite from the work. See Guidance on citing.

To link to this article DOI: http://dx.doi.org/10.1080/17522439.2019.1707859

Publisher: Taylor \& Francis

All outputs in CentAUR are protected by Intellectual Property Rights law, including copyright law. Copyright and IPR is retained by the creators or other copyright holders. Terms and conditions for use of this material are defined in the End User Agreement.

\section{www.reading.ac.uk/centaur}

\section{CentAUR}

Central Archive at the University of Reading 
Reading's research outputs online 


\section{Voice hearers' experiences of the Making Sense of Voices in an NHS setting}

Craig Steel $^{1}$, Joachim Schnackenberg ${ }^{2,6}$, Zoe Travers $^{4}$, Eleanor Longden ${ }^{3}$, Emily Greenfield $^{4}$, Lynette Meredith $^{1}$, Hayley Perry ${ }^{7}$, Dirk Corstens ${ }^{5}$

*Correspondence: School of Psychology and Clinical Language Sciences, University of Reading, Whiteknights, Reading, RG6 6AL. U.K. e-mail: c.steel@ reading.ac.uk. Tel: +44118 3787550.

${ }^{1}$ School of Psychology and Clinical Language Sciences, University of Reading, U.K.

${ }^{2}$ Stiftung Diakoniewerk Kropp \& St Ansgar gGmbH Kropp, Kropp, Germany.

${ }^{3}$ Greater Manchester Mental Health NHS Foundation Trust, Manchester, U.K.

${ }^{4}$ Berkshire Healthcare Foundation Trust, Bracknell, U.K.

${ }^{5}$ MET ggz Roermond and Maastricht University, Netherlands.

${ }^{6}$ EFC Institut, Hohn, Germany.

${ }^{7}$ Thames Valley Clinical Trials Unit, University of Reading, U.K.

Word Count: 3,983. 


\begin{abstract}
The Making Sense of Voices (MsV) approach (Romme \& Escher, 2000) has become established within large sections of the voice hearing community, as well as being adopted by some professional mental health workers. However, there has been limited research to assess this intervention. A recent case series using the MsV approach (Steel et al., 2019) reported promising results across a number of standardised outcome measures. The current study reports on the voice hearers' experience of having received the $\mathrm{MsV}$ intervention, through the use of 'exit interviews' conducted as part of the case series. Individual participants' experiences indicated a range of reactions to the intervention. Positive outcomes appeared to relate to a better understanding of voice hearing experiences and a greater sense of control over voices. Not all participants reported a positive experience of communicating with their voices. Outcomes are discussed within the context of potential common and distinct 'ingredients' of the MsV approach, compared to other approaches to working with distressing voices.
\end{abstract}




\section{Introduction}

Mental health interventions for distressing voice hearing experiences have typically evolved as part of wider 'packages' aimed at people diagnosed with a specific condition, such as schizophrenia. Cognitive behaviour therapy (CBT) is one such intervention, and is typically associated with a moderate therapeutic effect (Lincoln \& Peters, 2019; van der Gaag, Valmaggia \& Smit, 2014). The development of psychological interventions for voices has been limited by a number of issues. First, there is debate about which clinical factors should be prioritised when evaluating a psychological intervention (Birchwood and Trower, 2006; Steel, Garety, Freeman et al., 2007; Thomas et al., 2014). CBT trialists have been criticised for adopting a quasi-neuroleptic approach, in which the outcome measures employed are the same as those adopted within pharmaceutical trials (Birchwood and Trower, 2006), typically the Positive and Negative Symptom Scale (PANSS, Kay et al., 1989). Second, the dominance of research reporting group-based results means that relatively little is known about who responds well to which kind of intervention. Third, there is limited development and evaluation of transdiagnostic approaches to working with voices. Consequently, there is ongoing activity in the development and evaluation of a variety of approaches to working with voices, including mindfulness (Chadwick et al., 2009), acceptance and commitment therapy (Veiga-Martínez, Pérez-Álvarez \& García-Montes, 2008) and relating therapy (Hayward, Bogen-Johnston, \& Deamer, 2018).

One approach that has been disseminated by experts-by-experience and experts-bytraining members of the survivor-led Hearing Voices Movement is that proposed by Romme and Escher (2000) in their publication 'Making Sense of Voices'. This approach is also known as the 'Maastricht' approach and as Experience Focussed Counselling (Schnackenberg, Fleming \& Martin, 2017). The intervention is based on a number of principles. Most notable is the premise that voice hearing may often start as part of a 
sociopsychologically and biographically meaningful reaction to traumatic life events. Further, that voice content (including the original and actual intention of the voice) is relevant and should be engaged with, and that this might include actively dialoguing with the voice(s) (Corstens, Longden \& May, 2012).

Following a period of establishing a therapeutic alliance, the Making Sense of Voices $(\mathrm{MsV})$ approach consists of three main phases. First, an engagement phase occurs, where the voice hearer works with a mental health practitioner to discuss basic coping strategies. Second, is an assessment phase, where the current voice's content is formulated. This will make reference to the wider context of the voice hearer's personal relationships, along with their past and current life events. This formulation is termed a 'construct'. Finally, this new understanding is employed to facilitate a change in the voice hearer's relationship with their voice(s). Ideally, the voice hearer becomes less submissive to, and threatened by, the voice hearing experience. This latter phase may also include dialoguing with the voice(s). This is a process in which voice content is listened to and verbally engaged with by the voice hearer. It can be done by the voice hearers themselves or as part of a formal process facilitated by a mental health professional. The overall aims are: (i) to enable the resolution of conflict (between the voice hearer and their voice(s)) (ii) to develop a new understanding of the meaning behind what the voices say; and (iii) to foster a more mutual (constructive) relationship with the voice(s).

There have been two recent studies which represent an early stage in the development of an evidence base for the MsV approach; - a small randomised controlled trial (Schnackenberg et al., 2017) and a case series (Steel et al., 2019). The latter involved the participation of fifteen voice hearers and suggested the potential for moderate to large effect sizes for both voice frequency and distress. As noted above, there is debate about which outcomes should be used when evaluating interventions for voice-related distress. Clearly, 
the views of voice hearers themselves are an important contribution to this debate. Therefore, alongside quantitative evaluation, where individual differences are not as visible, it would seem important to attend to the personal experience of individuals who engage in such interventions (Corstens et al., 2014). In this regard, early studies indicate that the MsV approach is trauma-sensitive (Schnackenberg, Fleming \& Martin, 2018a), and functions within a transdiagnostic approach to understanding distress (Schnackenberg, Walker, Fleming \& Martin, 2018b).

The current study extracted information from the exit interviews conducted with all participants who engaged in the MsV approach within the recently completed case series (Steel et al., 2019). Our aim was to assess whether the intervention, and in particular the 'dialoguing with voices' aspect of the approach, was acceptable to those who engaged with it. We also aimed to try and better understand the experiences of those who did not seem to benefit. In this regard, the assessment of participants' personal experiences of an intervention also contributes to the monitoring of any potential adverse reactions, an issue which has attracted increased attention in recent years (Jonsson et al., 2014).

\section{Methods and Materials}

\section{Participants}

All participants were recruited through an NHS setting (Berkshire Healthcare Foundation Trust). To be eligible for the Steel et al. (2019) case series, potential participants had to report currently distressing voices, as determined by a rating of 2 or above on the 'Intensity of Distress' item on the Psychotic Symptoms Rating Scale for voices (Haddock, McCarron, Tarrier \& Faragher, 1999). They also had to be aged 18-65 and to have had no significant 
history of organic or drug/alcohol factors implicated in the aetiology of experiences often referred to as psychotic symptoms. They had to be able to speak English and have a fixed abode. There were no other restrictions on the entry criteria regarding diagnosis, although participants had to have had recorded contact with mental health services at the point of recruitment. Fifteen participants consented to participate in the case series, of whom three withdrew from the study during the intervention phase, and therefore did not take part in the exit interviews. Table 1 reports the baseline characteristics of the 12 participants in the current study.

Table 1 about here

The study was given NHS ethical approval by the South Central Berkshire B (15/SC/0013) and the protocol was registered (ISRCTN5437085).

\section{Exit Interviews}

The exit interview was designed to assess satisfaction with the intervention, outcomes of the intervention, and the personal experience of dialoguing with voices. The questions were generated by members of the research team, which included a voice hearer. The interviews were conducted by a research assistant (EG), who endeavoured to create as free and as open an exchange as possible (Moriarty, 2011), to give participants the opportunity to provide honest feedback about their experiences. 
All participants completed the $\mathrm{MsV}$ intervention, and the interviews were conducted between three and five months after the final session. The interviews lasted between 4 and 19 minutes (mean duration $=10.3$ minutes; median $=8.2$ minutes $),$ and were digitally recorded and transcribed verbatim.

\section{Data Analysis}

All interviews were transcribed. The responses to each question are reported individually. Where relevant responses were grouped into categories by one of the research team (LM) and checked by the project lead (CS).

\section{Results}

The participant numbers used to identify the quotations below (P1 to P15) are derived from the Steel et al. (2019) case series, in which Figure 1 includes individual graphs reporting the weekly voice-related distress ratings for each participant. Three participants did not take part in the current study (P11, P13 and P14); - one due to having moved out of the area and two due to having disengaged from the study.

Q1. When you think back on your work with (therapist name) about your voices, can you tell me what outcome of the sessions you were most happy with?

Nine out of 12 participants identified an outcome that 'they were most happy with'. This included, reductions in voice hearing and/or related distress (P2, P4), developing rapport and trust with the therapist, and being open to discussing problems with the therapist (P5, P6, P12), getting a better understanding of what causes voices and gaining control over them (P8), being better able to talk to their voices (P3, P10) and 
learning strategies to deal with voices (P15). One participant did not provide a response (P7). Two participants provided outcomes they were unhappy with, which were the sessions having the wrong focus (P1) and there not being enough sessions to achieve what was hoped for (P4).

Q2. When you think back on your work with (therapist name) about your voices, can you tell me what outcome of the sessions you were most unhappy with?

Five out of 12 participants identified outcomes of the sessions they were 'most unhappy with'. P6 stated there were no negative outcomes and P7 did provide a response. Negative responses included $\mathrm{P} 1$ and $\mathrm{P} 4$ who referred to the answers given to Q1. Other negative outcomes were that the sessions were too focused on voices alone (P2); that some sessions seemed to exacerbate symptoms (P9) but also that more sessions may have been useful (P9); and that the sessions could be effortful and affect physical health (P10).

Q3. Do you think you are more, or less, in control of your voice hearing experience than before the voices work started? Or has there been no change? (please explain) If more in control by how much (0-100\%)?

Six participants reported feeling more in control of their voices (P1, P3, P6, P7, P8 and P15). The amount of increased control they felt varied between 50-95\%. However, one of these participants stated that their increased control was due to their 
medication (P7). Four stated that there had been no change in control (P2, P5, P9 and P10) and two stated that their control varied (P4 and P12).

Reasons given for how participants came to have some change in control over their voices were: getting rid of voices and reducing voice related distress (P3, P8); feeling less threatened by voices (P5); talking about, acknowledging and accepting the voices $(\mathrm{P} 1, \mathrm{P} 2)$; having a better understanding of voices $(\mathrm{P} 4, \mathrm{P} 8, \mathrm{P} 15)$ and challenging the thought process behind voices (P8).

Q4. Do you think you are more, or less, distressed by your voice hearing experience than before the voices work started? Or has there been no change? (please explain) If more in control by how much (0-100\%)?

Six participants reported feeling less distressed by their voice hearing experience (P1, P2, P3, P6, P8 and P15) than before the intervention started. Three participants said their distress had remained the same (P4, P5 and P12), two said that their distress varied (P7 and P8) and one (P10) reported more distress. The participants feeling less distressed reported feeling a decrease of between 40 to $95 \%$.

Reasons given for a reduction in voice-related distress were: being able to talk back to voices (P1); knowing that one can get rid of voices (P3); no longer feeling ashamed of the voices (P6); improved understanding of the voices and learning that the voice may be trying to help (P6, P8), and being more curious about one's experiences $(\mathrm{P} 15)$.

Q5. Overall, how satisfied are you with what was achieved during the sessions on a scale of 0 (not satisfied at all) to 10 (very satisfied)? 
The mean satisfaction score was 8.3 (range 5-10). Two participants gave the lowest rating of 5 (P9 and $\mathrm{P} 12)$.

The remaining questions were specifically focused on the voice dialogue aspect of the MsV intervention.

Q6. Were you encouraged to try and communicate with your voices? Yes / No (Please explain).

All 12 participants stated that they were encouraged to try and communicate with their voices. Participants described the experiences as being 'scary but good' (P2, P3), 'strange at first' (P6), 'initially awkward' (P8) and 'stressful' (P12). Some participants also identified positive outcomes from talking to the voices, including feeling that communicating worked or felt good (P1, P2, P4, P8, P10) and eventually felt easier and less threatening (P3).

Q7\&8. When this was first discussed, were you happy with the idea of communicating with your voices? Yes/ No (Please explain) (Q7).

By the end of the sessions, were you happy with the idea of communicating with your voices? Yes/ No (Please explain) (Q8).

Five participants stated that they were happy with the initial idea of communicating with their voices (P3, P5, P6, P7, P10) and seven reported being uncertain or nervous (P1, P2, P4, P8, P9, P12, P15). At the end of the sessions, eight participants were happy with communicating with their voices (P1, P6, P10, P15). P7, who had initially been positive about voice dialogue, did not respond to this question. Overall, three participants moved from an initial negative 
response to communicating with their voices to a positive one (P1, P2, P15), whilst three participants remained unhappy (P8, P9, P12).

Some early reactions to communicating directly or indirectly with the voices are characterised by the following quotes:

P3. "Scary at first, but after identifying who the voice was, it was easy and felt no threat."

P6: "Strange at first, it seemed very strange. It was quite a revelation really, some of the things that the voices said were unexpected; I guess I hadn't really expected it to reply". P8. "Unsure, panic, slight fear, it sounded a bit out there and alternative."

P9: "I didn't really want to do that. I think part of me was frightened, frightened of what might happen, what I might find. I think I was just really frightened".

P10. "I just wanted it out of the way and to find out what was actually going on."

P15. "Thought it was strange, but the more I did it, the less strange it was, I don't feel strange doing it now. The more I talk to them, the less evident they become...because I'm more aware of what causes it"

The following quotes refer to participants' views at the end of the sessions about whether they were happy with the idea of communicating with their voices:

P3: "Yes very positive."

P6. "Yes."

P8. "Not happy, I think it's powerful but hard to do, that's probably my keenness to wanting to achieve results, just being able to connect all the time, it's really powerful stuff.", 
P9: "Still quite frightened."

P10: "Yes, it was the only way we could communicate with them, it was an easier way because the voices had their own say."

P15. "Yes, it makes sense to me now, I understand why you're meant to do it. I talk to my mum as well. She's dead now but it's helpful and comforting."

Q9. Do you feel that things stayed the same, something got achieved or nothing got achieved by communicating with your voices? (Please explain).

Eleven participants stated that something had been achieved by communicating with their voices. This included the voices no longer being an issue (P2); reducing and controlling their voices $(\mathrm{P} 3, \mathrm{P} 7)$; having a better understanding of their voices (P4, P6, P10, P15); talking to the therapist being helpful (P5, P8); and having an awareness of the voices (P9, P12). One participant said that nothing was achieved (P1).

The following quotes represent the range and variety of the outcomes from the $\mathrm{MsV}$ intervention.

P1. "Nothing achieved. A lot of the work depended on the therapist."

P6. "Quite a lot got achieved, realised that feelings about things I hadn't been able to cope with in the past had been projected onto the voice, and that the voice was looking after them. Realised that the voice wasn't against me, but was trying to protect me and helping me cope with feelings. Time to get back responsibility of the voices and my own behaviour."

P8: "Having the team approach was good, having you guys, the appointments, ringing up and things were helpful. The therapist was a skilled, trustworthy practitioner, and that really helped." 
P9: 'I'm more aware that I can have my say and that the voices can't control or take over that. It was hard to implement sometimes, hard to put into practice. It's kind of more of an awareness."

P12: “It hasn't stopped the voices which is what I want. I got more insight through the study, I understand that sometimes the voice is there for a reason but it makes me very susceptible to psychotic behaviour."

P15: "Achieved, I have more knowledge and understanding of what causes voices, the more you know, you're going to be less frightened."

\section{Discussion}

Overall, satisfaction with the MsV approach was high. However, there was a range of reactions within the twelve participants. Varied outcomes are likewise reflected within Figure 1 of the Steel et al. (2019) case series where individual participant quantitative outcomes are reported. This underscores the importance of attending to the individual participants experiences of an intervention when it has yet to develop an established evidence-base.

Positive responses to the intervention were based on both a good therapeutic relationship and on factors specific to voice hearing; such as increased control, reduced distress and a better understanding of the role of voices within an individual's life. The latter would seem specific to the $\mathrm{MsV}$ approach, with several participants referring to their relationship with their voices. The number of participants who were happy to engage in dialogue with their voices grew from five at the start of the study to eight at the end. However, it should also be highlighted that seven participants had reservations about engaging in voice dialogue, with three of these maintaining their reservations until the end of 
the intervention. The level of initial anxiety is perhaps unsurprising given the clinical setting for this work (UK NHS services), where the premise of voice dialogue is likely to be at odds with the medically-orientated approach to which participants will have been exposed. The fact that three participants, ( $25 \%$ of the sample), remained hesitant about voice dialogue at the end of the intervention requires some consideration. That most, but not all, participants saw a positive role for voice dialogue suggests that mental health workers adopting this approach need to maintain a strong collaborative relationship in which the concerns of the voice hearer are heard and respected. Most importantly, the intervention should not be delivered within an 'expert-led' framework in which the person delivering MsV advocates the approach to such an extent that voice hearer feels obliged to engage with it (Corstens, Escher, Romme \& Longden, 2019).

It is important to try and understand the 'process of change' within any psychosocial intervention. Actively engaging with voices is a potentially distinct mechanism of change within the MsV approach. For those participants who were able to engage in dialogue with their voices, there was a sense that important information was obtained which contributed to a change in the voice hearers relationship with their voice(s). In this respect it is worth comparing the MsV approach with the recently developed avatar therapy, which involves training voice hearers to respond assertively to a computer generated representation of one of their voices (Craig et al., 2018). This form of assertive communication is contrary to the exploratory communication adopted within the $\mathrm{MsV}$ approach. Thus it is likely that there are both common and distinct 'active ingredients' within the two approaches which may contribute to a positive outcome. Given the varied individual outcomes highlighted in the current study, it may be that those who did not benefit from the MsV approach (such as P9) may have benefited more from the avatar approach. Future research should aim to establish predictors of individual suitability for different interventions. 
For some individuals, voices may be associated with distressing life events (Longden, Corstens, Escher, \& Romme, 2012; Romme \& Escher, 2000, 2010), and the MsV approach is based on understanding a voice as a meaningful psychosocial response to adversity. It emerged that many of the current participants were able to develop a changed perspective towards their voice hearing experience, through the creation of a 'construct'. This is a form of psychosocial formulation, which identifies links between voices and past or present experiences, relationships, and their circumstances (Corstens et al., 2019). The development of this explanatory framework was associated with reduced distress for some participants. This is in line with earlier findings (Schnackenberg et al., 2018a; Schnackenberg et al., 2018b), and suggests that seeing voices as emotionally meaningful was a valuable part of the intervention. Of note, some (but not all) cognitive behavioural approaches to working with voices also incorporate the use of a formulation which integrates adverse life events with the individual presentation of distressing voices. The current study would therefore indicate that this is an important element of a CBT approach and may be a limitation of the avatar approach.

A clear limitation of the current study is that three participants, (20\%) of the Steel et al., (2019) sample, did not consent to interviews after withdrawing from the study. It is possible that these individuals had a negative experience of the $\mathrm{MsV}$ intervention. Given the early point at which two participants disengaged, it is also possible that the prospect of dialoguing with voices was a cause for concern. Neither reached the dialoguing stage of the intervention. Further, although a voice hearer from our research team contributed to the development of the exit interview, it lacked input from a wider group of voice hearers. There may, therefore, have been some bias introduced into what the exit interview actually assessed. It would also have been preferable to engage independent researchers to conduct the interviews; however resource limitations prevented this. 
Overall, the current study highlights the importance of core therapeutic, or counselling, skills when working with people who hear voices. These include developing a trusting relationship and adopting a non-judgemental stance. Also, anxiety about the prospect of engaging in the $\mathrm{MsV}$ approach is not uncommon and does not always dissipate. This issue would indicate the need for practitioners to receive adequate training and supervision in order to maximise therapeutic potential and minimise the likelihood of adverse reactions. Finally, the outcomes identified within the current study may be important when developing measures of psychosocial interventions for distressing voices. They might include the level of engagement with one's voices, whether interventions enhanced the voice hearer's sense of control, and whether the voice hearer believes that they have moved towards a more helpful understanding of their experiences.

\section{Declaration of Interest Statement}

Three authors (DC, EL \& JS) have received financial payments for delivering teaching or supervision on the MsV approach. There are no other reported conflicts of interest.

\section{Acknowledgements}

We would like to thank the other contributors to this research, both voice hearers and non voice hearers. Specifically, Suzanne Engelen as one of our trainers in the MsV approach, Annie Beyer, Rachel Manser, Tim Walker, Ffion Jones, Megan Kerr and Kathy Greenwood. We would also like to thank the fifteen voice hearers who participated in the study, along with the staff of Berkshire Healthcare NHS Foundation Trust who facilitated the project. 


\section{References}

Aleman, A. \& Laroi, F. (2008). Hallucinations: The Science of Idiosyncratic Perception.

American Psychological Association: Washington, DC.

Birchwood, M. \& Trower, P. (2006). The future of cognitive-behavioural therapy for psychosis: not a quasi-neuroleptic. British Journal of Psychology, 188, 107-8.

Chadwick, P., Hughes, S., Russell, D., Russell, I. \& Dagnan, D. (2009). Mindfulness groups for distressing voices and paranoia: a replication and feasibility trial. Behavioural and Cognitive Psychotherapy, 37, 403-412.

Corstens, D., Escher, S., Romme, M., \& Longden, E. (2019). Accepting and working with voices: The Maastricht Approach. In A. Moskowitz, M. J. Dorahy, \& I. Schäfer (Eds.), Psychosis, trauma and dissociation: Emerging perspectives on severe psychopathology (2nd Ed.) pp. 381-396. Chichester: Wiley-Blackwell.

Corstens, D., Longden, E. \& May, R. (2012). Talking with voices: exploring what is expressed by the voices people hear. Psychosis: Psychological, Social and Integrative Approaches, 4, 95-104.

Corstens, D., Longden, E., McCarthy-Jones, S., Waddingham, R. \& Thomas, N. (2014).

Emerging perspectives from the Hearing Voices Movement: implications for research and practice. Schizophrenia Bulletin, 40(Suppl. 4), S285 - S294.

Haddock, G., McCarron, J., Tarrier, N. \& Faragher, E.B. (1999). Scales to measure dimensions of hallucinations and delusions: the psychotic symptom rating scales (PSYRATS). Psychological Medicine, 29, 879-89.

Hayward, M., Bogen-Johnston, L., \& Deamer, F. (2018). Relating Therapy for distressing voices: Who, or what, is changing?, Psychosis, 10, 132-141. 
Jonsson, U., Alaie, I., Parling, T., \& Arnberg, F. K. (2014). Reporting of harms in randomized controlled trials of psychological interventions for mental and behavioral disorders: A review of current practice. Contemporary Clinical Trials, 38, 1-8.

Kay, S.R., Opler, L.A., Lindenmayer, J.P. (1989). The positive and negative syndrome scale (PANSS): Rationale and standardisation. British Journal of Psychiatry, 155: suppl 7, $59-65$.

Lincoln, T. \& Peters, E. (2019). A systematic review and discussion of symptom specific cognitive behavioural approaches to delusions and hallucinations. Schizophrenia Research, 203, 66-79.

Longden, E., Corstens, D., Escher, S., \& Romme, M. (2012). Voice hearing in a biographical context: a model for formulating the relationship between voices and life history. Psychosis, 4(3), 224-234.

Longden, E., Corstens, D., Escher, S. \& Romme, M. (2012). Voice hearing in a biographical context: A model for formulating the relationship between voices and life history. Psychosis, 4, 224-234.

May, K., Strauss, C., Coyle, A., \& Hayward, M. (2014). Person-based cognitive therapy groups for distressing voices: A thematic analysis of participant experiences of the therapy. Psychosis, 6(1), 16-26.

Moriarty, J. (2011). Qualitative methods overview. Methods review, 1. National Institute for Health Research. London. Retrieved October 5, 2013 from http://eprints.lse.ac.uk/41199.

Romme, M. \& Escher, S. (2000). Making Sense of Voices. London: Mind.

Romme, M., \& Escher, S. (2010). Personal history and hearing voices. In F. Larøi \& A. Aleman (Eds.), Hallucinations: A guide to treatment and management (pp. 233-256). 
New York, NY, US: Oxford University Press.

Schnackenberg, J. K., Fleming, M. \& Martin, C. (2017). A randomised controlled pilot study of experience focussed counselling with voice hearers. Psychosis: Psychological, Social and Integrative Approaches, 9, 12-24.

Schnackenberg, J., Fleming, M. \& Martin, C. R. (2018a). Experience Focussed Counselling with Voice Hearers as a Trauma-sensitive Approach. Results of a Qualitative Enquiry. Community Mental Health Journal. Advance online publication. doi: 10.1007/s10597-018-0294-0.

Schnackenberg, J., Fleming, M., Walker, H. \& Martin, C. R. (2018b). Experience Focussed Counselling with Voice Hearers: Towards a Trans-diagnostic Key to Understanding Past and Current Distress - A Thematic Enquiry. Community Mental Health Journal. Advance online publication. doi: 10.1007/s10597-018-0280-6.

Steel, C., Garety, P.A., Freeman, D., Craig, E., Kuipers, E., Bebbington P., ......Dunn G. (2007). The multidimensional measurement of the positive symptoms of psychosis. International Journal of Methods of Psychiatric Research, 16, 88-96.

Steel, C., Schnackenberg, J., Perry, H., Longden, E., Greenfield, E. \& Corstens, D. (2019). Making Sense of Voices: a case series. Psychosis, 11, 3-15.

van der Gaag M, Valmaggia LR, Smit F. (2014). The effects of individually tailored formulation-based cognitive behavioural therapy in auditory hallucinations and delusions: a meta-analysis. Schizophrenia Research, 156, 30-7.

Veiga-Martínez, C., Pérez-Álvarez, M., \& García-Montes, M., J. (2008). Acceptance and 
Commitment Therapy Applied to Treatment of Auditory Hallucinations. Clinical Case Studies, 7(2), 118-135. 


\begin{tabular}{|c|c|c|c|c|c|c|c|c|}
\hline \multirow{2}{*}{$\begin{array}{l}\text { Participa } \\
\text { nt } \\
\text { Number }\end{array}$} & \multirow[t]{2}{*}{$\begin{array}{c}\mathrm{Ag} \\
\mathrm{e}\end{array}$} & \multirow[t]{2}{*}{$\begin{array}{l}\text { Gende } \\
\quad r\end{array}$} & \multirow[t]{2}{*}{$\begin{array}{c}\text { Ethnicit } \\
y\end{array}$} & \multirow[t]{2}{*}{ Diagnosis } & \multirow{2}{*}{$\begin{array}{l}\text { Anti-psychotic } \\
\text { medication } \\
\text { (Chlorpromazi } \\
\text { ne equivalent } \\
\text { dose in } \\
\mathrm{mg} / \text { day) }\end{array}$} & \multicolumn{3}{|c|}{$\begin{array}{c}\text { Baseline score on the } \\
\text { PSYRATS }\end{array}$} \\
\hline & & & & & & $\begin{array}{c}\text { Tota } \\
\text { I }\end{array}$ & $\begin{array}{c}\text { Frequenc } \\
y \\
\text { subscale }\end{array}$ & $\begin{array}{c}\text { Distres } \\
\text { s } \\
\text { subscal } \\
\text { e } \\
\end{array}$ \\
\hline 1 & 63 & $\begin{array}{c}\text { Femal } \\
\mathrm{e}\end{array}$ & $\begin{array}{l}\text { White } \\
\text { British }\end{array}$ & $\begin{array}{l}\text { Schizophreni } \\
\mathrm{a}\end{array}$ & 266.67 & $\begin{array}{r}31.0 \\
0 \\
\end{array}$ & 8.00 & 16.00 \\
\hline 2 & 40 & Male & $\begin{array}{l}\text { White } \\
\text { British }\end{array}$ & $\begin{array}{l}\text { Schizophreni } \\
\text { a }\end{array}$ & 466.67 & $\begin{array}{r}26.0 \\
0 \\
\end{array}$ & 7.00 & 12.00 \\
\hline 3 & 59 & Male & $\begin{array}{l}\text { White } \\
\text { British }\end{array}$ & $\begin{array}{l}\text { Psychosis } \\
\text { NOS }\end{array}$ & 466.67 & $\begin{array}{r}33.0 \\
0 \\
\end{array}$ & 7.00 & 16.00 \\
\hline 4 & 49 & $\begin{array}{c}\text { Femal } \\
\mathrm{e}\end{array}$ & $\begin{array}{l}\text { White } \\
\text { British }\end{array}$ & $\begin{array}{l}\text { Schizoaffecti } \\
\text { ve disorder }\end{array}$ & 800.00 & $\begin{array}{r}31.0 \\
0\end{array}$ & 6.00 & 19.00 \\
\hline 5 & 57 & Male & $\begin{array}{l}\text { White } \\
\text { British }\end{array}$ & $\begin{array}{l}\text { Schizophreni } \\
\text { a }\end{array}$ & 1200.00 & $\begin{array}{r}30.0 \\
0 \\
\end{array}$ & 7.00 & 13.00 \\
\hline 6 & 51 & $\begin{array}{c}\text { Femal } \\
\mathrm{e}\end{array}$ & $\begin{array}{l}\text { White } \\
\text { British }\end{array}$ & $\begin{array}{l}\text { Emotionally } \\
\text { unstable } \\
\text { personality } \\
\text { disorder }\end{array}$ & 300.00 & $\begin{array}{r}36.0 \\
0 \\
\end{array}$ & 10.00 & 18.00 \\
\hline 7 & 47 & $\begin{array}{l}\text { Femal } \\
\mathrm{e}\end{array}$ & $\begin{array}{l}\text { Black or } \\
\text { Black } \\
\text { British - } \\
\text { African }\end{array}$ & $\begin{array}{l}\text { Schizophreni } \\
\text { a }\end{array}$ & 200.00 & $\begin{array}{r}33.0 \\
0 \\
\end{array}$ & 7.00 & 18.00 \\
\hline 8 & 42 & $\begin{array}{c}\text { Femal } \\
\mathrm{e}\end{array}$ & $\begin{array}{l}\text { White } \\
\text { British }\end{array}$ & $\begin{array}{l}\text { Emotionally } \\
\text { unstable } \\
\text { personality } \\
\text { disorder }\end{array}$ & 277.78 & $\begin{array}{r}36.0 \\
0 \\
\end{array}$ & 8.00 & 20.00 \\
\hline 9 & 47 & $\begin{array}{c}\text { Femal } \\
\mathrm{e}\end{array}$ & $\begin{array}{l}\text { White } \\
\text { British }\end{array}$ & $\begin{array}{l}\text { Schizophreni } \\
\text { a }\end{array}$ & 400.00 & $\begin{array}{r}29.0 \\
0 \\
\end{array}$ & 7.00 & 14.00 \\
\hline 10 & 25 & $\begin{array}{l}\text { Femal } \\
\mathrm{e}\end{array}$ & $\begin{array}{l}\text { Asian } \\
\text { or } \\
\text { Asian } \\
\text { British - } \\
\text { Pakista } \\
\text { ni }\end{array}$ & $\begin{array}{l}\text { Psychosis } \\
\text { NOS }\end{array}$ & 400.00 & $\begin{array}{r}28.0 \\
0\end{array}$ & 10.00 & 10.00 \\
\hline 12 & 46 & $\begin{array}{c}\text { Femal } \\
\mathrm{e}\end{array}$ & $\begin{array}{l}\text { White } \\
\text { British }\end{array}$ & $\begin{array}{l}\text { Schizoaffecti } \\
\text { ve disorder }\end{array}$ & 1050.00 & $\begin{array}{r}25.0 \\
0 \\
\end{array}$ & 7.00 & 12.00 \\
\hline 15 & 56 & Male & $\begin{array}{l}\text { White } \\
\text { British }\end{array}$ & $\begin{array}{l}\text { Schizophreni } \\
\text { a }\end{array}$ & 400.00 & $\begin{array}{r}38.0 \\
0\end{array}$ & 11.00 & 20.00 \\
\hline
\end{tabular}

Table 1: Demographic details of the participants.

Note: Participant numbers cross-reference with those adopted in the Steel et al. (2018) case series. 
